Environmental Conservation (2014) 41 (4): 303-310 (C) Foundation for Environmental Conservation 2014. The online version of this article is published within an Open Access environment subject to the conditions of the Creative Commons Attribution licence $<$ http://creativecommons.org/licenses/by/3.0/ $>$.

\title{
Salient values, social trust, and attitudes toward wolf management in south-western Alberta, Canada
}

\author{
CARLY C. SPONARSKI ${ }^{13 *}$, JERRY J. VASKE ${ }^{2}$, ALISTAIR J BATH ${ }^{3}$ AND \\ MARCO M. MUSIANI ${ }^{1}$ \\ ${ }^{1}$ Faculty of Environmental Design, University of Calgary, Alberta, Canada, ${ }^{2}$ Human Dimensions of Natural Resources, Colorado State University, \\ Fort Collins, Colorado, USA, and ${ }^{3}$ Department of Geography, Memorial University, St Fohn's, Nemfoundland, Canada \\ Date submitted: 14 April 2013; Date accepted: 2 December 2013; First published online 28 January 2014
}

\section{SUMMARY}

Shared values, public trust in an agency, and attitudes can influence support for successful conservation initiatives. To understand these relationships, this paper examines the role of social trust as a partial mediator between salient values similarity and attitudes toward wolves in south-western Alberta, Canada. Rural residents in this area face increasing wolf depredation on livestock. Data were obtained from a mail questionnaire ( $n=566$ respondents, response rate $=70 \%$ ) sent to rural residents in three municipal districts in south-western Alberta. Attitudes were predicted to directly influence behavioural intention to support or oppose wolf management. Most respondents held slightly similar values as the management agency and minimally trusted the agency to effectively manage wolves. As predicted, social trust in the agency served as a partial mediator between salient value similarity and attitudes toward wolves. Salient value similarity was also a strong predictor of attitudes toward wolves. Attitudes toward wolves predicted behavioural support. Thus, social trust of the management agency can influence attitudes and management preferences concerning a species. When dealing with human-wildlife conflict, social trust should be examined to understand the context of the problem.

Keymords: Beliefs, salient value similarity, social trust, structural equation model, wildlife management, wolves

\section{INTRODUCTION}

Social trust in the management agency is an integral component in establishing cooperation between the agency and the public (Beierle \& Konisky 2000; Cvetkovich \& Winter 2004; Höppner 2009) and influences the public's support of management decisions (Winter et al. 1999; Cvetkovich \& Winter 2004; Liljeblad \& Borrie 2006). As defined here, social

*Correspondence: Carly Sponarski, Department of Geography, Memorial University, St John's, Newfoundland, Canada A1B 3X9 Tel: +1 7098646127 e-mail: csponarski@gmail.com trust is the willingness to rely on those who have the formal responsibility to develop policies and take appropriate action (Cvetkovich \& Winter 2003, 2004). Sometimes people do not accept a specific resource management option because they do not trust the agency (Cvetkovich \& Winter 2004; Nyaupane et al. 2009) or they believe the agency holds different values than them (Needham \& Vaske 2008). When society trusts the governing agency, citizen compliance with management plans and policies increases (Braithwaite \& Levi 1998; Cook 2002). Trust can be built through positive personal interactions between the public and the agency, receptiveness of public input by the managers, and the perceived effectiveness of the agency (Stern 2008a, b). Understanding the nature of social trust and building trust among constituents should be a management priority (Höppner 2009; Nyaupane et al. 2009).

Unfortunately, social trust in natural resource agencies has declined in recent decades (Shindler et al. 2002; Leahy et al. 2004; White \& Eiser 2005; Davenport et al. 2007). Trust is fragile, as negative actions tend to have greater impacts than positive actions (White \& Eiser 2005; Davenport et al. 2007). People may base their trust judgments on whether they feel that the agency shares similar goals, thoughts, values and opinions. This approach is known as salient value similarity (SVS), but has also been referred to as salient similarity, perceived shared values, and perceived similarity (see for example Siegrist et al. 2001; Cvetkovich \& Winter 2003; Earle 2004; Needham \& Vaske 2008). SVS and social trust have been used in the risk literature (Beierle \& Konisky 2000; Sjöberg 2000, 2001; Cvetkovich \& Winter 2003, 2004), in environmental and protected area planning, and in endangered species and wildfire management (Beierle \& Konisky 2000; Cvetkovich \& Winter 2003; Winter et al. 2004; Vaske et al. 2007; Nyaupane et al. 2009). SVS and social trust have had limited application to wildlife management and have not been employed with the controversial issue of wolves and large carnivores.

Here we examine the theoretical relationships between SVS, social trust, attitudes toward wolves and behavioural intentions to support or oppose wolf management options in Canada. Theory (for example cognitive hierarchy, see below) predicts that individuals may directly assess the appropriateness of wolf management based on their attitudes (Fishbein \& Ajzen 2010; Vaske \& Manfredo 2012) and, in turn, trust and perceived shared values are hypothesized 
to influence attitudes toward wolves (Vaske et al. 2007). Managers dealing with wolf issues often have to work with citizens who have had conflict with wolves (such as wolf depredation on livestock). In these situations, people tend to feel that government is not doing enough to mitigate conflict (Nie 2003).

\section{Wolf management in south-western Alberta}

Livestock losses to wolves in Alberta have become common, and ranchers routinely request reductions in wolf numbers (Musiani et al. 2005). A licence is required by non-landowners to hunt wolves during big game seasons, but no restriction is set on the number of wolves killed. Landowners may kill wolves year-round without restriction on deeded or leased public land and within $8 \mathrm{~km}$ of their land (Musiani et al. 2005). Compensation is provided if the government agency determines that livestock loss was due to wolves. Compensation, however, may not be an effective tool when ranchers know that wolves will continue to depredate their livestock.

The Alberta Provincial Government has not detailed the current status of wolves in the province and its management protocol. Without an approved policy, the Alberta Fish and Wildlife Division (AFWD), a division of Alberta Sustainable Resource Development (ASRD), manages wolves on a caseby-case basis. Conservationists may perceive the AFWD as not being proactive in dealing with the recovery of wolves. Residents who have experienced depredation may perceive the AFWD as not doing enough to combat wolf depredation, or may see this 'laissez-faire' approach as permission to take management into their own hands. Little is known about rural residents' trust in the management agency and how this may affect attitudes toward wolves and their own individual behavioural intention to shoot wolves.

\section{Theoretical framework}

The cognitive hierarchy suggests that attitudes and beliefs mediate the relationship between values and behaviour (Schwartz 1992; Whittaker et al. 2006). The theory distinguishes stable but abstract general values (Rokeach 1973; Homer \& Kahle 1988) from more specific cognitions (such as attitudes and beliefs) toward some object (for example wolves or wolf management) (Eagly \& Chaiken 1993). These cognitions are arranged in a 'hierarchy' along a continuum from the more general (for example SVS) to the specific (for example trust, attitudes toward wolves), and build upon one another (Homer \& Kahle 1988). Specific attitudinal variables are more likely to predict behaviours than more general measures like values (Fiske \& Taylor 2002; Whittaker et al. 2006). Research has applied this cognitive hierarchy to evaluations and behaviour associated with wildlife (Fulton et al. 1996; Manfredo \& Fulton 1997; Zinn et al. 1998).

Vaske et al. (2007) used a portion of the cognitive hierarchy to examine the relationships between SVS, trust in agency,

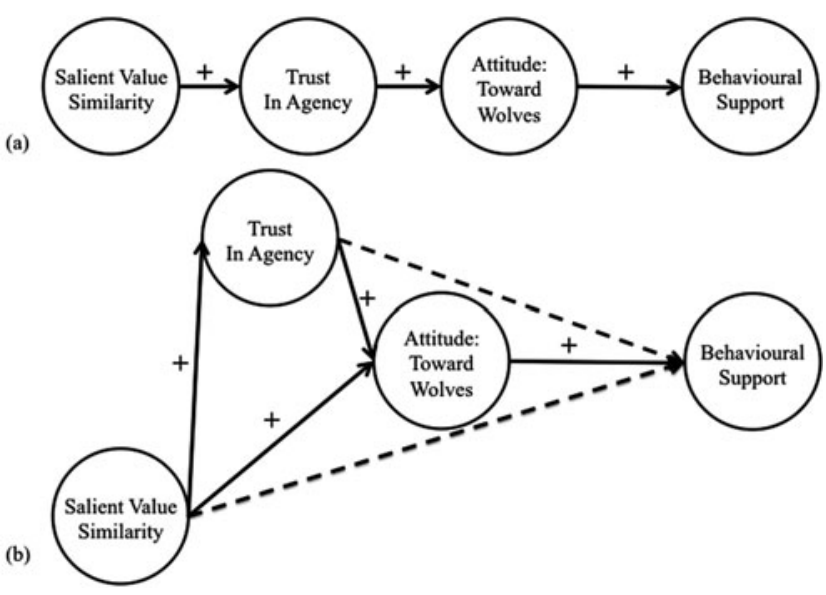

Figure 1 Hypothesized relationships between salient value similarity (SVS), social trust, attitudes toward wolves, and behavioural support: $(a)$ the full mediation model and $(b)$ the partial mediation model. In the partial mediation model, SVS has a direct influence on attitudes, as well as an indirect influence via social trust. In the full mediation model social trust fully mediates the relationship between SVS and attitude. Dashed lines signify no predicted relationships between the concepts, plus signs on the arrows denote the hypothesized relationships between the concepts.

and attitudes toward wildfire. We adapted this model to the context of attitudes towards wolves, and extended the framework to include the relationship between attitudes and behavioural support (namely behavioural intention). Past research has repeatedly shown that the best predictor of behavioural intentions (such as support for or opposition to wolf management) is often a person's attitude toward the same object (for example wolves) (Fishbein \& Ajzen 2010).

Based on previous research (see Siegrist \& Cvetkovich 2000; Siegrist et al. 2000; Williams et al. 2002; Vaske et al. 2007), we hypothesized a partial mediation model (Fig. 1). These predictions were based on past research that has repeatedly demonstrated that attitudes trump other predictors in these types of models (Fishbein \& Ajzen 2010). We predicted that: (1) as SVS increases, social trust in the management agency will increase; (2) as SVS increases, attitudes toward wolves will become more positive; (3) SVS will not influence the specific behavioural support; (4) as social trust increases, attitudes toward wolves will become more positive, (5) social trust will mediate the relationship between SVS and attitudes toward wolves; (6) social trust in the management agency will not influence specific behavioural support; and (7) as attitudes toward wolves become more positive, willingness to support non-lethal options will increase.

\section{METHODS}

\section{Study area}

The study area included three rural municipal districts (MDs) of south-western Alberta, Canada: Foothills, Pincher Creek, 
and Willow Creek. Wolves and livestock were present in all MDs surveyed, although wolf distributions were concentrated on the western side of the MDs (in the foothills). In the last five years, the human population has increased in Foothills (19\%), Pincher Creek (1\%), and Willow Creek (2\%) (JetteNantel et al. 2011; Statistics Canada 2011). The economy of the area is supported by agriculture, forestry, and oil and gas development. The dominant land use is domestic livestock grazing, mostly cattle, which takes place on both public and private lands (Statistics Canada 2011).

\section{Sampling protocol}

We contacted 1059 people and invited them to participate in the study; 809 residents (age 18 or older) agreed to participate. We selected respondents randomly, proportional to each MD's population, using telephone directories. Given the poor mobile phone coverage in rural south-western Alberta, most residents have landlines and are listed in the telephone directories. Within the household, we selected the individual with the 'next birthday' for the study. We used the initial telephone contact to verify the postal address, select a named individual within the household, and obtain their verbal agreement to participate in the study.

The following day, questionnaires were posted by firstclass mail to the individuals who had agreed to undertake the survey. Questionnaires were sent out between 22 June and 7 July 2009. The package included a cover letter, a survey, and a self-addressed stamped envelope for return of the questionnaire. A reminder postcard was sent to nonrespondents between 3 July and 23 July 2009. Individuals who did not return their questionnaire two weeks after the postcard received an additional copy of the questionnaire.

The overall response rate, for those who agreed to participate, was $70 \%$ (566 completed surveys $/ 809$ surveys mailed). Questionnaires were received from the Foothills $(n=285 ; 68 \%$ return rate for MD), Pincher Creek $(n=$ $91 ; 73 \%$ return rate for MD), and Willow Creek $(n=190$; $71 \%$ return rate for MD). Approximately $53 \%$ of respondents were male with the sample population's age ranging from 48-57 years old. Forty-seven per cent of respondents were educated to high school level, while an additional $41 \%$ had a post-secondary degree. The average length of residency was 19 years.

\section{Variables within the model}

We focused on 14 survey items, organized in four latent constructs: SVS (four items), social trust in the agency (four items), attitudes toward wolves (two items), and behavioural support toward wolf management options (four items). The survey items used in each of the latent constructs came from previous studies involving these topics (Naughton-Treves et al. 2003; Vaske et al. 2007). Items were measured on sevenpoint scales ranging from 'strongly disagree' $(-3)$ to 'strongly agree' (3).
SVS was measured using questions taken from Siegrist et al. (2000) and Vaske et al. (2007). For example, 'with respect to wolf management, I feel that Alberta Sustainable Resource Development (ASRD): (a) shares similar values as me; $(b)$ thinks in a similar way as me; $(c)$ takes similar actions as I would; and $(d)$ shares similar goals as me' (See Table 1 for full wording of all questions included in analysis).

Social trust was measured using questions adapted from Vaske et al. (2007). Two questions pertained to 'trust in management': 'I trust the ASRD knows how to: (a) effectively manage wolf populations; and $(b)$ respond to damage by wolves'. A second indictor was 'trust in information', based on two questions: 'with respect to wolf management, I trust ASRD to provide: $(a)$ the best available information to decide what action I should take regarding wolf management; and $(b)$ truthful information about safety issues related to wolves'.

Attitudes toward wolves were measured using two survey items. Two items measured tolerance through respondents' views on perceived population maintenance (NaughtonTreves et al. 2003): 'wolf populations should be maintained in (a) Alberta for future generations and $(b)$ in my municipal district for future generations'.

Four survey items were used to measure the variable behavioural support toward wolves in regards to their protection and what respondents would do if they came across a wolf. The four variables were: $(a)$ 'I would support lethal measures of managing wolves; (b) I would support fully protecting wolves in Alberta; $(c)$ If I were hunting and saw a wolf I would shoot it; and $(d)$ If I saw a wolf near my cattle I would shoot it'. All behavioural support variables listed above, except for the second item (I would support fully protecting wolves in Alberta), were reverse coded.

\section{Analysis}

Confirmatory factor analysis was used to empirically verify the legitimacy of the conceptual distinctions among the observed variables (Kline 2011). Standardized factor loadings were used to gauge the relative impact of each survey item on the latent construct. Internal consistency of the SVS, social trust, attitude and behavioural support latent indices were investigated using Cronbach's alpha (Vaske 2008). A structural equation model was used to assess whether social trust had a mediating role between SVS and attitudes. Social trust could either be a full mediator between the independent variable (SVS) and dependent variable (attitudes) or a partial mediator, (MacKinnon 2008; Hayes \& Preacher 2013). We used the program Lisrel 8.8 to fit two separate models (full versus partial mediation) using the covariance matrix. We examined the overall model fit using four goodness-of-fit indices: chi-square $\left(\Delta \chi^{2}, \chi^{2} / d f\right)$, the comparative fit index (CFI; an acceptable CFI value is $>0.90$ ), root mean square error of approximation (RMSEA; an acceptable RMSEA value is between 0.05 and 0.08 ), and the normed fit index (NFI; an acceptable NFI value is $>0.95$ ) (Hu \& Bentler 1999; Skogen \& Thrane 2008). 
Table 1 Indicators for SVS, social trust, attitudes toward wolves and behavioural intention. ${ }^{\text {a }}$ The questions were on a seven-point Likert scale where $-3=$ strongly disagree; $-2=$ moderately disagree; $-1=$ slight disagree; $0=$ neutral; $1=$ slight agree; $2=$ moderately agree; and $3=$ strongly agree. ${ }^{b}$ Data were reversed coded before running the confirmatory factor analysis, reliability analysis and the structural equation model.

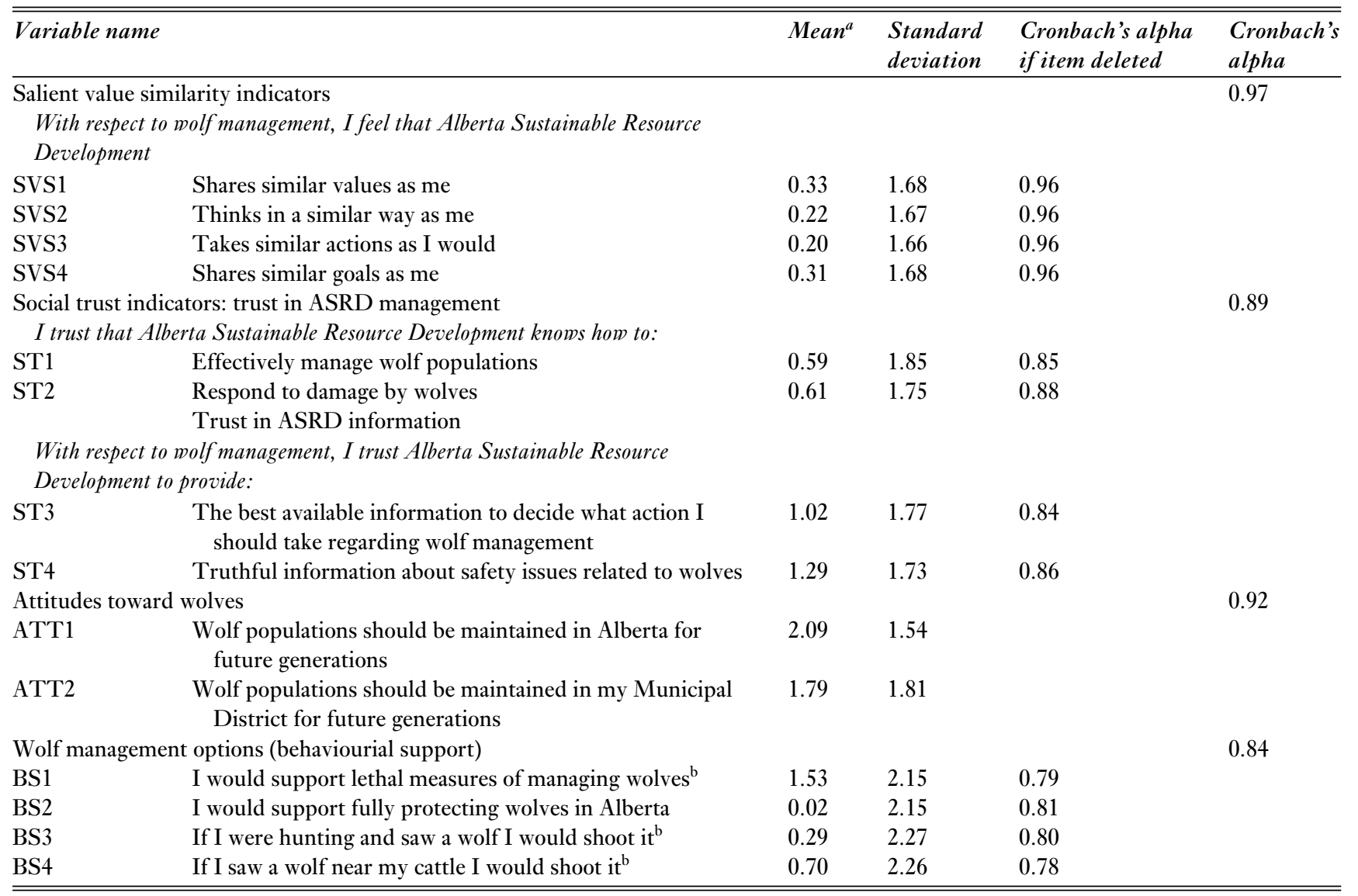

\section{RESULTS}

\section{Scale reliabilities and factor analysis}

We used confirmatory factor analysis to verify that all of the items loaded on their associated constructs with all factor loadings being $\geq 0.70$ on the latent variable (see Fig. 2). The internal reliability for the latent variable SVS was 0.97 (Table 1). South-western Alberta residents were neutral in their belief that they shared the same values (SVS1: $\mathrm{M}=$ $0.33, \mathrm{SD} \pm 1.68$ ), thoughts (SVS2: $\mathrm{M}=0.22, \mathrm{SD} \pm 1.67$ ), actions (SVS3: $\mathrm{M}=0.20, \mathrm{SD} \pm 1.66$ ), and goals (SVS4: $\mathrm{M}=0.31, \mathrm{SD} \pm 1.68)$ as the AFWD managers. The observed variables in trust in agency index had a reliability of 0.89 . The respondents were neutral in terms of trust of AFWD to effectively manage wolf populations ( $\mathrm{ST} 1: \mathrm{M}=0.59$, $\mathrm{SD} \pm 1.85)$ and respond to damage by wolves (ST2: $\mathrm{M}=$ $0.61, \mathrm{SD} \pm 1.75$ ). Respondents were also neutral in their trust of AFWD to provide the best information available regarding methods used in wolf management (ST3: $\mathrm{M}=$ $1.02, \mathrm{SD} \pm 1.77)$, safety issues and timely information sharing (ST4: $\mathrm{M}=1.29, \mathrm{SD} \pm 1.73$ ). The reliability for attitudes toward wolves was 0.92 . On average, residents thought that wolf populations should be maintained in Alberta (ATT1:
$\mathrm{M}=2.09, \mathrm{SD} \pm 1.54)$ and in their respective municipal district (ATT2: $\mathrm{M}=1.79, \mathrm{SD} \pm 1.81$ ). The behavioural support latent variables had a reliability of 0.84 . In general, residents supported lethal management (BS1: $M=1.53$, $\mathrm{SD} \pm 2.15$ ), did not support full protection of wolves (BS2: $\mathrm{M}=0.02, \mathrm{SD} \pm 2.15)$, but were unsure if they would shoot a wolf if they saw one while hunting (BS3: $M=0.29$, $\mathrm{SD} \pm 2.27$ ) or saw a wolf near cattle (BS4: $\mathrm{M}=0.70, \mathrm{SD} \pm$ 2.26).

\section{Social trust as a mediator}

The data supported the hypothesized relationships (Fig. 1b; 7 out of the 7 hypothesized relationships). The fit indices for the full mediation model (Fig. 1a) were acceptable $\left(\chi^{2}=197.60, d f=72\right.$, NFI (0.982), CFI (0.989) and RMSEA (0.056)). Similarly, the fit indices for the partial mediation model (Fig. $1 b)$ were also acceptable $\left(\chi^{2}=183.91, d f=71\right.$, NFI (0.984), CFI (0.990) and RMSEA (0.054)) (Hu \& Bentler 1999) (Table 2). Based on the $\Delta \chi^{2}$ value $\left(\Delta \chi^{2}=13.69, d f=\right.$ $1, p<0.01)$, the partial mediation model had a better fit to the data (namely a statistically smaller $\chi^{2}$ ). Therefore, social trust 
Figure 2 Partial mediation structural equation model: path coefficients are standardized regression coefficients. All coefficients are statistically significant at $p<0.05$, except for the path between social trust and attitudes toward wolves, which is significant at $p<0.1$.

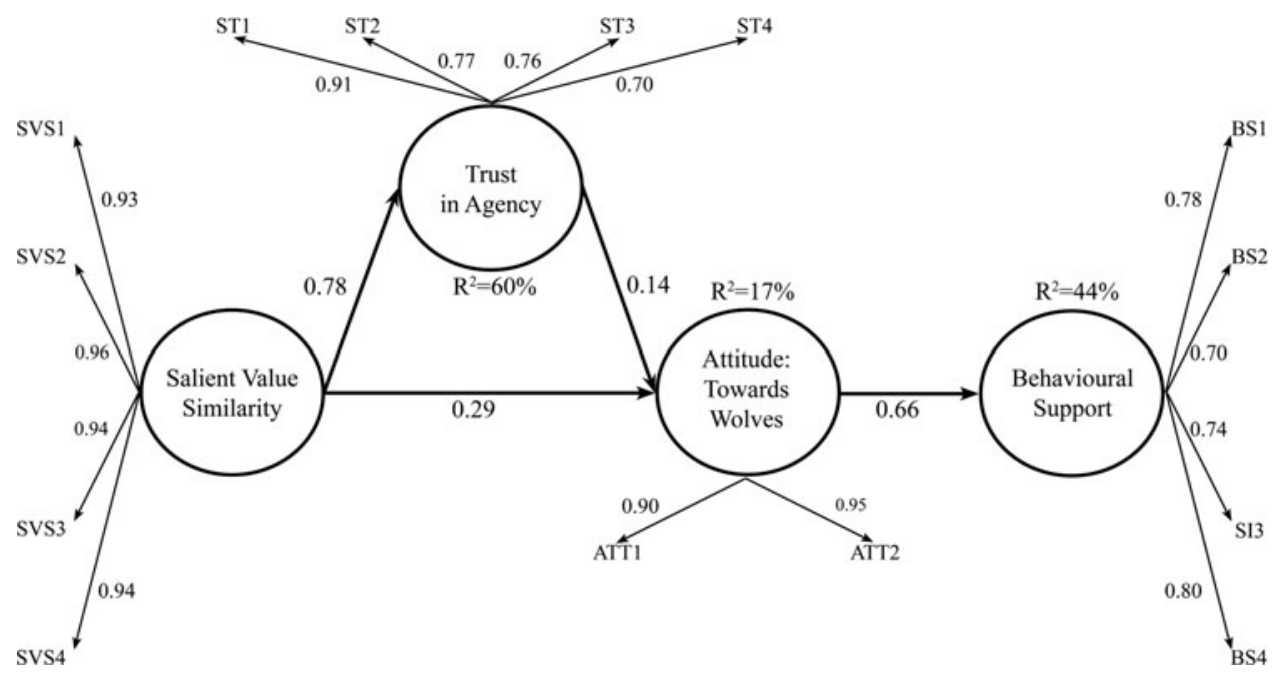

Table 2 Goodness-of-fit indices for the full and partial mediation structural equation models. NFI $=$ normed fit index, $\mathrm{CFI}=$ comparative fit index and RMSEA = root mean square error of approximation.

\begin{tabular}{lrrrllll}
\hline \hline Mediation models & \multicolumn{1}{c}{$\chi^{2}$} & $d f$ & p-value & $\chi^{2} / d f$ & NFI & CFI & RMSEA \\
\hline Full mediation model (Fig. 1b) & 197.60 & 72 & $<0.01$ & 2.74 & 0.982 & 0.989 & 0.056 \\
Partial mediation model (Fig. 1a) & 183.91 & 71 & $<0.01$ & 2.59 & 0.984 & 0.990 & 0.054 \\
$\Delta \chi^{2}$ (full - partial models) & 13.69 & 1 & $<0.01$ & & & & \\
\hline \hline
\end{tabular}

partially mediated the relationship between SVS and attitudes (hypothesis 5).

As predicted, SVS and social trust did not have a direct statistical influence on behavioural support (both relationships were not significant, $p>0.05$; hypotheses 3 and 6 ). As salient value similarity increased, social trust in the management agency also increased $(B=0.78, p<0.05$; Fig. 2 , hypothesis 1). We identified a positive relationship between SVS and attitudes toward wolves $(B=0.30, p<0.05 ;$ Fig. 2 , hypothesis 2). Similarly, as predicted, positive attitudes toward wolves increased as social trust increased $(B=0.14, p<0.1$; hypothesis 4 ), but only at a 0.1 level of significance, and not at 0.05 . As hypothesized, as attitudes toward wolves became more positive, respondents tended to choose nonlethal forms of behaviour to deal with wolves $(B=0.67, p<$ 0.05 ; hypothesis 7 ).

\section{DISCUSSION}

We examined the relationships between SVS, social trust in a management agency, attitudes toward wolves, and behavioural support regarding wolf management. Our model provides applied and theoretical insights to understanding attitudes toward wolves and willingness to support or oppose various wolf management options. In general, public response to questions concerning their shared similar values, trust in the management agency and in their opinions about wolf management was just above average. Our model indicates that attitudes toward wolves and toward wolf management options may be partially determined by SVS and social trust in the management agency. This trust relationship is important for three reasons. First, the agencies' goals, objectives and management can be influenced by SVS and social trust. Second, the capacity for the management agency to persuade when communicating with constituents is strongly influenced by SVS and social trust (Vaske et al. 2007). Third, to work effectively with constituents requires a basic understanding of the different perspectives. Differences in values between the management agency and the constituents may lead to a decrease in the level of trust and, as the model indicated, a more negative attitude toward wolves (Cvetkovich \& Winter 2003). Combined, this could inhibit the management of wolves on the landscape in south-western Alberta.

To our knowledge, the SVS model has not been applied to wildlife resources. The positive relationships between all of the latent variables found in our results are consistent with previous research (Siegrist \& Cvetkovich 2000; Vaske et al. 2007). Regardless of the resource issue (for example nuclear power, wildland fire or wolves), the linkages between SVS, social trust, and attitudes toward the resource are similar. Social trust was a partial mediator between SVS and attitudes (SVS had both direct and indirect effects on attitudes through social trust). The relationship between SVS and attitudes was stronger than that of social trust and attitudes, but the strength of this relationship may vary depending upon the topic, whether it is nuclear power or wildfire. While the relationship between SVS and social trust in our study was substantial $(\beta=0.78)$ (Vaske 2008), the relationship between social trust and the attitude latent variable was statistically significant but of moderate $(B=0.30)$ strength compared to studies on other topics (such as nuclear power issues). 
It has been suggested that individuals' trust in agencies plays a particularly salient role in their decision-making when there is a high degree of perceived uncertainty (Dietz et al. 2007) or perceived ineffectiveness of an individual's ability to address the issue (Stern 2008a; Absher \& Vaske 2011). We hypothesize that less perceived individual control would lead to a need for greater trust in the agency. The perception that the event (such as livestock depredation) is common could lead to negative attitudes toward the species. Although there is a weak relationship between social trust and attitudes toward wolves, social trust in an agency has been shown to be a statistically significant contributing factor influencing a person's attitude towards wolves, thus this relationship warrants further testing.

For wildlife management agencies (such as the AFWD), establishing and maintaining trust with all interest groups is an ongoing challenge. The relationship strength between SVS and attitudes may also be due to other attributes, such as knowledge, experience and control, which can affect attitudes toward a resource (Glikman et al. 2011). In our wolf example, the management flexibility allowing rural residents to shoot wolves on their own property offers a greater degree of control than in the nuclear power issue, where an individual cannot really take effective action. The relationship between trust and attitudes may be influenced by an individual's perception of controllability of conflict. Higher levels of real or perceived individual control may reduce the need to have trust in the agency, as an individual can take care of the issue.

\section{Future research}

Although monitoring social trust of an agency is rare; such activities could become an indicator of the degree of conflict to expect. Social trust appears to influence attitudes. If management agencies better understand and monitor social trust and the linkages of trust with attitudes and behavioural support over time, they may be able to gauge which programmes (for example outreach efforts) are building trust with their constituents. Continued exploration into the relationship between salient values, social trust, attitudes and behavioural support items will help management agencies improve their relationship with residents, better integrate representative views of their rural constituency, and may lead to better success in implementing wolf management strategies. Such participation efforts can help increase social trust (Longstaff \& Yang 2008). Although speculative, trust appears to decline when communication between the public and government decreases or is non-existent (Brønn \& Brønn 2003). To improve trust, and therefore support for management decisions, managers must reach out to the public and integrate feedback from residents (Stern 2008b).

The questions examining SVS and social trust did not investigate whether people were actually aware of the values of AFWD. We did not provide any information to respondents regarding AFWD's wolf management strategy or test respondents' knowledge levels. Defining the management agency's values and comparing the level of social trust between people who are and are not aware of these values may prove enlightening. This would allow an exploration of the possible effect knowledge of agency values might have on SVS and social trust.

\section{CONCLUSIONS}

Our findings indicate social trust partially mediates the relationship between SVS and attitudes, and attitudes in turn influence behavioural support. Behavioural support was not influenced or mediated by either SVS or social trust. Model generalization could be further tested to examine how social trust may vary in importance to different natural resources (such as forestry, water, recreation, parks and protected areas, or wilderness). Lynam et al. (2007) suggested that social trust is context-specific, and thus models exploring the concept may lack the ability to be generalized to other resources; yet, we found similarities in the relationship between social trust in wolf management issues to those found with wildland fires (Vaske et al. 2007) and nuclear issues (Siegrist et al. 2000; Viklund 2003). Whether the mediating role of social trust may vary for different carnivore species remains an empirical question. Past research has shown that attitudes vary across large carnivores (Teel et al. 2002; Naughton-Treves et al. 2003; Glikman et al. 2011), but would social trust also vary? Because carnivores tend to be more controversial, social trust may be more important for carnivore management than for other wildlife species. Regardless of wildlife species or resource management issues, social trust may be an important topic for a management agency to address to ensure success in implementation of management actions.

\section{ACKNOWLEDGEMENTS}

We thank the individuals and organizations that contributed information and support: residents of south-western Alberta, research assistants and the Southern Alberta Montane Elk Research Project. Thank you to Dr T. S. Fung, Dr J. A. Glikman and the reviewers for discourse, guidance and suggestions. This project was supported by Alberta Conservation Association's Grants in Biodiversity, NSERC (Canada) and the Queen Elizabeth II Scholarship.

\section{References}

Absher, J.D. \& Vaske, J.J. (2011) The role of trust in residents' fire wise actions. International fournal of Wildland Fire 20: 318-325.

Beierle, T.C. \& Konisky, D.M. (2000) Values, conflict, and trust in participatory environmental planning. Fournal of Policy Analysis and Management 19: 587-602.

Braithwaite, V.A. \& Levi, M. eds. (1998) Trust and Governance. New York, NY, USA: Russell Sage Foundation.

Brønn, P.S. \& Brønn, C. (2003) A reflective stakeholder approach: co-orientation as a basis for communication and learning. Fournal of Communication Management 7: 291-303 
Cook, K.S. (2002) Trust in Society. New York, NY, USA: Russell Sage Foundation.

Cvetkovich, G.T. \& Winter, P.L. (2003) Trust and social representations of the management of threatened and endangered species. Environment and Behavior 35: 286-307.

Cvetkovich, G.T. \& Winter, P.L. (2004) Seeing eye-to-eye on natural resource management: trust value similarity, and action consistency/justification. In: Proceedings of the Fourth Social Aspects and Recreations Research Symposium, coord. P.T. Tierney \& D.J. Chavez, pp. 46-50. San Francisco, CA, USA: San Francisco State University.

Davenport, M.A., Leahy, J.E., Anderson, D.H. \& Jakes, P.J. (2007) Building trust in natural resource management within local communities: a case study of the Midewin National Tallgrass Prairie. Environmental Management 39: 353-368.

Dietz, T., Dan, A. \& Shwom, R. (2007) Support for climate change policy: social psychological and social structural influences. Rural Sociology 72: 185-214.

Eagly, A.H. \& Chaiken, S. (1993) The Psychology of Attitudes. New York, NY, USA: Harcourt Brace Jovanovich, Inc.

Earle, T.C. (2004) Thinking aloud about trust: a protocol analysis of trust in risk management. Risk Analysis 24: 169-183.

Fishbein, M. \& Ajzen, I. (2010) Belief, Attitude, Intention and Behaviour: An Introduction to Theory and Research. New York, NY, USA: Psychology Press Taylor and Francis.

Fiske, S.T. \& Taylor, S.E. (2002) Social Cognitition. Champaign, IL, USA: Sagamore Publishing Inc.

Fulton, D.C., Manfredo, M.J. \& Lipscomb, J. (1996) Wildlife value orientations: a conceptual and measurement approach. Human Dimensions of Wildlife 1: 24-47.

Glikman, J.A., Vaske, J.J., Bath, A.J., Ciucci, P. \& Boitani, L. (2011) Residents' support for wolf and bear conservation: the moderating influence of knowledge. European Fournal of Wildlife Research 58: 295-302.

Hayes, A.F. \& Preacher, K.J. (2013) Indirect and direct effects of a multicategorical causal agent in statistical mediation analysis. British Journal of Mathematical and Statistical Psychology (in press).

Homer, P.M. \& Kahle, L.R. (1988) A structural equation test of the value-attitude-behavior heirarchy. Fournal of Personality and Social Psychology 54: 638-649.

Höppner, C. (2009) Trust: a monolithic panacea in land use planning? Land Use Policy 26: 1046-1054.

Hu, L. \& Bentler, P.M. (1999) Cutoff criteria for fit indexes in covariance structure analysis: conventional criteria versus new alternatives. Structural Equation Modeling 6: 1-55.

Jetté-Nantel, S., Freshwater, D., Beaulieu, M. \& Katchova, A. (2011) Farm income variability and off-farm diversification in Canadian agriculture. Agriculture and Rural Working Paper Series, Statistics Canada, Agriculture Division, Ottawa, Ontario, Canada: 25 pp.

Kline, R.B. (2011) Principles and Practice of Structural Equation Modeling. Third edition. New York, NY, USA: Guilford Press.

Leahy, J.E., Davenport, M.A., Anderson, D.H. \& Jakes, P.J. (2004) Community trust in natural resource agencies: case studies from Illinois. In: Proceedings of the Fourth Social Aspects and Recreations Research Symposium, coord. P.T. Tierney \& D.J. Chavez, pp. 5157. San Francisco, CA, USA: San Francisco State University.

Liljeblad, A. \& Borrie, W.T. (2006) Trust in wildland fire and fuel management decisions. International fournal of Wilderness 12: 39 43.
Longstaff, P.H. \& Yang, S. (2008) Communication management and trust: their role in building resilience to 'surprises' such as natural disasters, pandemic flu, and terrorism. Ecology and Society 13: 3 .

Lynam, T., De Jong, W., Sheil, D., Kusumanto, T. \& Evan, K. (2007) A review of tools for incorporating community knowledge, preferences, and values into decision making in natural resources management. Ecology and Society 12: 5 [www document]. URL http://www.ecologyandsociety.org/vol12/iss1/art5/

MacKinnon, D.P. (2008) Introduction to Statistical Mediation Analysis. New York, NY, USA: Taylor \& Francis Group.

Manfredo, M.J. \& Fulton, D.C. (1997) A comparison of wildlife values in Belize and Colorado. Human Dimensions of Wildlife 2: 62 .

Musiani, M., Muhly, T., Gates, C.C., Callaghan, C., Smith, M. \& Tosoni, E. (2005) Seasonality and reoccurrence of depredation and wolf control in western North America. Wildlife Society Bulletin 33: $876-887$.

Naughton-Treves, L., Grossberg, R. \& Treves, A. (2003) Paying for tolerance: rural citizens' attitudes toward wolf depredation and compensation. Conservation Biology 17: 1500-1511.

Needham, M. \& Vaske, J.J. (2008) Hunter perceptions of similarity and trust in wildlife agencies and personal risk associated with chronic wasting disease. Society and Natural Resources 21: 197214.

Nie, M.A. (2003) Beyond Wolves: The Politics of Wolf Recovery and Management. Minneapolis, MN, USA: University of Minnesota Press.

Nyaupane, G.P., Graefe, A.R. \& Burns, R.C. (2009) The role of equity, trust and information on user fee acceptance in protected areas and other public lands: a structural model. Fournal of Sustainable Tourism 17: 501-517.

Rokeach, M. (1973) The Nature of Human Values. New York, NY, USA: Free Press.

Schwartz, S.H. (1992) Universals in the content and structure of values: theoretical advances and empirical tests in 20 countries. In: Advances in Experimental Social Psychology, ed. M.P. Zanna, pp. 1-66. San Diego, CA, USA: Academic Press.

Shindler, B., Brunson, M. \& Stankey, G. (2002) Social acceptability of forest conditions and management practices: a problem analysis. Report. US Department of Agriculture Forest Service Pacific Northwest Research Station, Portland, OR, USA.

Siegrist, M. \& Cvetkovich, G.T. (2000) Perception of hazards: the role of social trust and knowledge. Risk Analysis 20: 713720 .

Siegrist, M., Cvetkovich, G.T. \& Gutscher, H. (2001) Shared values, social trust, and the perception of geographic cancer clusters. Risk Analysis 21: 1047-1054.

Siegrist, M., Cvetkovich, G.T. \& Roth, C. (2000) Salient value similarity, social trust, and risk/benefit perception. Risk Analysis 20: 353-362.

Sjöberg, L. (2000) Factors in risk perception. Risk Analysis 20: 112.

Sjöberg, L. (2001) Limits of knowledge and the limited importance of trust. Risk Analysis 21: 189-198.

Skogen, K. \& Thrane, C. (2008) Wolves in context: using survey data to situate attitudes within a wider cultural framework. Society and Natural Resources 21: 17-33.

Statistics Canada (2011) 2011 Community profiles [www document]. URL http://www12.statcan.gc.ca/census-recensement/ 2011/dp-pd/prof/index.cfm? Lang $=\mathrm{E}$ 
Stern, M.J. (2008a) Coercion, voluntary compliance and protest: the role of trust and legitimacy in combating local opposition to protected areas. Environmental Conservation 35: 200-210.

Stern, M.J. (2008b) The power of trust: toward a theory of local opposition to neighboring protected areas. Society and Natural Resources 21: 859-875.

Teel, T.L., Krannich, R.S. \& Schmidt, R.H. (2002) Utah stakeholders' attitudes toward selected cougar and black bear management practices. Wildlife Society Bulletin 30: 2-15.

Vaske, J.J. (2008) Survey Research and Analysis: Applications in Parks, Recreation, and Human Dimensions. State College, Pennsylvania, USA: Venture Publishing, Inc.

Vaske, J.J., Absher, J.D. \& Bright, A.D. (2007) Salient value similarity, social trust and attitudes toward wildland fire management strategies. Human Ecology Reviem 14: 223232.

Vaske, J.J. \& Manfredo, M.J. (2012) Social psychological considerations in wildlife management. In: Human Dimensions of Wildlife Management, ed. 2, pp. 43-57. Baltimore, Maryland, USA: JHU Press.
Viklund, M.J. (2003) Trust and risk perception in Western Europe: a cross-national study. Risk Analysis 23: 727-738.

White, M.P. \& Eiser, J.R. (2005) Information specificity and hazard risk potential as moderators of trust asymmetry. Risk Analysis 25: 1187-1198.

Whittaker, D., Vaske, J.J. \& Manfredo, M.J. (2006) Specificity and the cognitive hierarchy: value orientations and the acceptability of urban wildlife management actions. Society and Natural Resources 19: $515-530$

Williams, C.K., Ericsson, G. \& Heberlein, T.A. (2002) A quantitative summary of attitudes toward wolves and their reintroduction (1972-2000). Wildlife Society Bulletin 30: 575-584.

Winter, P.L., Palucki, L.J. \& Burkhardt, R.L. (1999) Anticipated responses to a fee program: the key is trust. Fournal of Leisure Research 31: 207-226.

Winter, G., Vogt, C. \& McCaffrey, S. (2004) Examining social trust in fuels management strategies. Fournal of Forestry 102: 8-15.

Zinn, H.C., Manfredo, M.J., Vaske, J.J. \& Wittmann, K. (1998) Using normative beliefs to determine the acceptability of wildlife management actions. Society and Natural Resources 11: 649. 